\title{
Scientific Realism and Further Underdetermination Challenges
}

\author{
Mario Alai ${ }^{1}$ (ID
}

Received: 30 December 2020 / Accepted: 3 March 2021 / Published online: 14 March 2021

(c) The Author(s) 2021

\begin{abstract}
In an earlier article on this journal I argued that the problem of empirical underdetermination can for the largest part be solved by theoretical virtues, and for the remaining part it can be tolerated. Here I confront two further challenges to scientific realism based on underdetermination. First, there are four classes of theories which may seem to be underdetermined even by theoretical virtues. Concerning them I argue that (i) theories produced by trivial permutations and (ii) "equivalent descriptions" are compatible with the truth of standard theories; instead (iii) "as if" versions of standard theories are much worse from the point of view of theoretical virtues; finally (iv) mathematically intertranslatable theories either may become empirically decidable in the future, or can be discriminated by theoretical virtues, or realists may simply plead ignorance about their claims. Secondly, I consider Stanford's underdetermination with respect unconceived alternatives, arguing that it essentially relies on the pessimistic meta-induction from the falsity of all past theories. Therefore, it can be resisted by (a) considering the radical advancement of present with respect to past science, and (b) arguing with selective realism that past successful theories, even if false, always included some true components.
\end{abstract}

Keywords Empirical underdetermination - Scientific realism - Theoretical virtues · Empirically equivalent theories · Confirmation · Evidence $\cdot$ Unconceived alternatives $\cdot$ Kyle Stanford $\cdot$ Mathematically equivalent theories $\cdot$ Equivalent descriptions $\cdot$ Pessimistic meta-induction $\cdot$ Selective realism

Mario Alai

mario.alai@uniurb.it

1 DiSPeA - Università degli Studi di Urbino Carlo Bo, via Curiel 41, 47521 Cesena, FC, Italy 


\section{The Empirical Underdetermination of Theories and Theoretical Virtues}

The argument form the empirical underdetermination of theories against scientific realism is that in principle any body of empirical data, no matter how large, is compatible with an infinite number of possible incompatible theories. But since the confirmation of a theory depends exclusively on the class of its empirical consequences, no particular theory can be confirmed to the exclusion of its alternatives. Hence, there can be no reasons to believe in the truth of theories.

In an earlier article on this journal (Alai 2019) I argued that although this argument has been used as an argument against realism ever since the antiquity, until the last century it raised mainly a philosophical problem which very seldom seriously troubled practicing scientist. The reason is that confirmation does not depend only on empirical consequences, and a choice among empirically equivalent theories is allowed by theoretical virtues (like explanatory and unifying power, fecundity - the capacity to yield novel testable predictions (Alai 2014b) plausibility, consistency and consilience with the rest of accepted theories and background beliefs, simplicity, etc. —See Glymour 1980, Kosso 1992, Psillos 1999, 171-176). Moreover, I argued that the theories selected in this way are not just pragmatically or aesthetically better, but as more probably (and/or largely) true.

At present, however, in quantum mechanics it seems that not even theoretical virtues allow to choose among many competing theories and interpretations. Given the stunning empirical success of the standard theory, the alternative proposals are designed to yield the same predictions at least concerning what is currently observable, but they are not in principle empirically equivalent, and experimental tests discriminating some of them from the standard theory might be forthcoming, or are already attempted. When we deal with different interpretations of the standard theory, however, they are in principle experimentally undecidable. Nor can they be considered as indifferent from a realist point of view, because they make incompatible ontological and metaphysical claims.

Yet, the reason why we are unable to decide among them is not that all of them possess the required theoretical virtues at an equal degree, or that virtues themselves cannot offer evidence for the truth of a theory. Rather, it is that none of the competing alternatives possess such virtues to a sufficient degree. For instance, Bohm's theory postulates an implausible and otherwise unsupported instant dependence of everything on everything else (Dieks 2017, p. 309). The many worlds interpretations contrast with our very basic belief about the uniqueness of the universe, and they are otherwise unsupported; the causation of the wave collapse by an act of consciousness is at odds with the firm belief of moderns that the spirit cannot directly act on inanimated matter, and it is otherwise unsupported; the Copenhagen interpretation avoids all these shortcomings, but it provides no picture of the unobservable mechanisms and no explanation of the empirical regularities; etc. Therefore our provisional conclusion should not be that we are uncertain which one of these alternatives is true, but that probably 
none of them is (completely) true, and we should look for a better one. In fact, the historical record is that all theories which in the past did not have all the required theoretical virtues have been replaced in due course.

But what if we never progress in experimental techniques enough to test currently untestable but in principle testable theories, and we never find a better theory, i.e., one with sufficient theoretical virtues? Even in that unfortunate case, we should simply conclude that as a matter of fact our quest for knowledge encounters insuperable limits in the quantum world; this however is quite different from saying that we cannot gather enough justification for any theory on any subject, as claimed by the empirical underdetermination argument.

Further, this would not make realism impossible even in microphysics itself: in fact, physicists ordinarily discuss about unobservable objects, like elementary particles, fields, strings, membranes, etc., and such discourse is not understood instrumentalistically, as a mere façon de parler, but as referring to actual entities (Dieks 2017, 311-312). This is because (as argued for instance by Cordero 2001, S307) all of the main competitors share some key assumptions (the quantum state as a peculiar physical field, the central role of Schrödinger's equation in the dynamics, a strong form of ontic-structural nonseparability, internal molecular shapes, atomic and quark structure, etc.). Thus, while we currently ignore the truth on the questions on which they diverge, and perhaps we will ignore it forever, there are also matters about which we have well founded beliefs and probably even knowledge.

Yet, there are further ways in which underdetermination has been claimed to refute realism, which I shall examine here. One is Kyle Stanford's transient but recurrent underdetermination; another is the idea that there are entire classes of theories which must be underdetermined even by theoretical virtues: for instance, theories produced by trivial permutations, "as if" versions of standard theories, mathematically intertranslatable theories, or what Goodman and Putnam call "equivalent descriptions".

\section{Underdetermination Even by Theoretical Virtues}

Antirealists have objected that in certain cases not even theoretical virtues could discriminate between competing theories. Let's examine four kinds of cases.

\subsection{Trivial Permutations}

First, theoretical virtues couldn't discriminate between a theory $\mathbf{T}_{\mathbf{1}}$ and a theory $\mathbf{T}_{\mathbf{2}}$ cooked up by commuting everywhere two terms of $\mathbf{T}_{\mathbf{1}}$. But obviously this would be just the same theory, expressed in two different languages. ${ }^{1}$ So, this undecidability is not a problem for scientific realism.

\footnotetext{
1 Stanford (2009a), footnote 9, lists a number of works discussing the question of when, and to what extent, empirically equivalent theories can be considered just different formulations of one and the same theory: Glymour (1970, 1977, 1980, 2013) Sklar (1982), Halvorson (2012, 2013)..
} 


\subsection{Instrumentalist Reductions}

Also, Kukla held that any theory $\mathbf{T}$ will be equally supported as:

- T': the claim that $\mathrm{T}$ has true observable consequences, but it is false;

- T": the claim that the world behaves in the way B described by T when observed, and in a different way B' when not observed (Kukla 1993, 1996).

Further similar alternatives are mentioned by Fine, van Fraassen, Lyons, Stanford, etc. (Alai 2014a, § 2). However, as noticed by Stanford (2001), this would reduce the specific problem of scientific underdetermination to the metaphysical skepticism of a Cartesian evil demon. Moreover, and more importantly, these alternatives are much worse than their standard counterparts from the point of view of theoretical virtues. For instance, while $\mathbf{T}$ explains its empirical consequences, $\mathbf{T}$ ' (i.e., the theory that $\mathbf{T}^{\prime}$ is empirically right but false) does not. In general, no theory stripped of all its theoretical claims can explain anything: "the hypothesis that it is raining explains why the streets are wet-but 'The phenomena are as if it were raining' does not" (Musgrave 2006, 2007; Alai 2014a, § 2). Moreover, an instrumentalized version of 'T, like $\mathbf{T}$ ', cannot be a rival to $\mathbf{T}$, because it is a logical consequence of T (Laudan and Leplin 1991, 456-457).

As for T", it is more complex and less confirmed than $\mathbf{T}$, because it postulates two different behaviors of the world (B and B'), of which only B is supported by our evidence. Laudan and Leplin (1993) argue that the claim by which T" differs from $\mathbf{T}$ (i.e., that the world behaves differently when not observed) is superfluous (since it has no empirical consequences), implausible (since it implies a violation to the uniformity of nature we have never observed) and untestable.

Thus, Kukla's algorithms fail to produce theories that are equivalent not just empirically, but also from the point of view of theoretical virtues. This failure does not refute the general point that in principle for any theory there may be thousands of empirically equivalent theories. It doesn't even refute the possibility that some of those alternative theories are undetermined also by theoretical virtues. ${ }^{2}$ However, Kukla's failure deprives of any support the claim that for any theory there are empirically and theoretically equivalent theories. ${ }^{3}$

\subsection{Mathematically Intertranslatable Theories}

Philosophers have suggested various examples of empirically equivalent theories which apparently cannot be decided even by theoretical virtues, because they are mathematically intertranslatable. Such examples include:

\footnotetext{
2 One argument showing this possibility is offered by Bangu (2006, 273-274). But this is not a necessity, and it needs not hold for all cases. On this see also the discussion in Acuña and Dieks (2014, § 4.2.3). I agree with Acuña and Dieks $(2014, \S 5)$ that the existence of particular couples of theories empirically and theoretically underdetermined is possible.

${ }^{3}$ On this point see also the discussion by Acuña and Dieks (2014, § 4.1.2).
} 
1. Newtonian mechanics (based on force) vs. Lagrangian or Hamiltonian mechanics (based on a principle of minimal action) (Putnam 1978a, p.153, 1981, pp. 81-82);

2. theories introducing fields vs. theories using action at distance with retarded potentials (ibid.);

3. Heisenberg's matrix mechanics vs. Schrödinger's wave mechanics and Feynman's path integral formulation ${ }^{4}$;

4. Newton's cosmology, assuming that the entire universe is at rest, vs. a theory with the same laws of motion and gravitational attraction, but assuming that the universe is moving with some constant velocity in some given direction (van Fraassen 1980);

5. Newtonian mechanics with its gravitational field vs. GTR's curvature of spacetime

6. different cosmological models of the GTR assuming different global topological features which are empirically undistinguishable inside the light cones of even idealized eternal observers. ${ }^{6}$

These couples of theories are more closely related than the alternative quantum theories considered above, which need not be mathematically intertranslatable. Thus, one could suggest with stronger grounds that these alternatives are just different formulations of the same theory, therefore they are not mutually incompatible, but can be simultaneously true. However, this answer is not easily available to scientific realists: perhaps they can accept the suggestion that there is simply no fact of the matter whether the universe is at absolute rest or not, hence the alternatives of item 4. of this list are really the same theory; but realists should hold that there is fact of the matter about whether quantum waves are real or not; whether there are fields and no action at a distance, or vice-versa; whether spacetime is flat or curve; which are its topological features; etc.

Still, realists can deal with these cases by three (not mutually exclusive) strategies:

(1) They can argue that these theories are mathematically intertranslatable only because their diverging ontological claims are not fully expressed by their formalisms nor reflected in their empirical predictions. But perhaps one day they will be developed so to express them, and become empirically decidable. For instance, as long as only the geometrical formalisms of the Ptolemaic and Copernican systems were considered, they were mathematically intertranslatable. But soon it became possible to attribute to their diverging claims a physical meaning (for instance by specifying their different dynamics), and so also deriving different empirical predictions from them.

(2) Further, realists may insist that in spite of the empirical and mathematical equivalence of certain theories, we can choose between their different ontologies by

\footnotetext{
4 Putnam (1978b), p. 555; Friedman (1983), pp.165 ff.; Fano (2005), p. 166.

5 Earman (1993). Instead, for John Norton (2008) this example simply involves two notational variants of a single theory (see footnote 17 above); see also Stanford (2009a).

${ }^{6}$ Earman (1993); see also Stanford (2009a).
} 
theoretical virtues and plausibility criteria. For instance, Hamiltonian mechanics has actually been preferred to Newtonian mechanics.

(3) Finally, realists may simply grant that, although there is a fact of the matter about those different ontologies, we (or at least, the theories at hand) are simply unable to tell anything about them: as suggested by Stanford (2001, 2009a), what such theories diverge about is a "surplus content", something beyond their proper scope, which they have no warrant to assume, and which we need not believe in order to take them seriously. Granting that we may be de facto unable to know the truth about some particular subject is not just compatible with realism, but entailed by it.

In particular, this third strategy is adopted by structural realists, who believe that we should exclusively focus on the mathematical structures of reality, as opposed to entities and ontologies, because structures are all that we can possibly know-as held by epistemic structural realists (Poincaré 1902; Worrall 1989, etc.), or even all that really exists - as claimed by ontic structural realists (Ladyman and Ross 2007, French and Ladyman 2011, etc.). From this point of view, therefore, when alternative theories attribute to their subject matter the same structure, their difference may be discounted and no underdetermination arises (French 2011).

In general, structural realism may not be a satisfactory solution to the problem of empirical underdetermination, because one and the same body of data may be always be accounted for by theories attributing not only different ontologies, but also different structures (Lyre 2011). ${ }^{7}$ But this difficulty does not arise for mathematically untertranslatable theories, for (in some important sense) they describe the same structure. Also, typical scientific realists may not be satisfied with structural realism, because they are committed to a realist interpretation of entities and ontologies. But again, it seems that in this particular case realism may be better defended by humility than by presumption, i.e. by conceding that the subject escapes our knowledge, at least for the time being.

\subsection{Same Content in Different Schemes}

Again, it may be remarked that theoretical virtues cannot discriminate between theories which Goodman and Putnam call "equivalent descriptions", for they are not just mathematically intertranslatable, but have also an equivalent theoretical content. The following are ways of getting equivalent descriptions: describing reality alternatively by speaking of rabbits or of rabbit-stages; conceptualizing rain as an object or as a process (Quine 1958); using as primitives both objects and mereological sums, or just objects; using lines and points or just lines ${ }^{8}$; describing spacetime events by different simultaneity concepts; assuming that the Earth is motionless and the Sun

\footnotetext{
7 Lyre also thinks that actual examples of underdetermination are too few to support the general underdetermination thesis, but again, the question is why.

${ }^{8}$ Putnam (1978b: 130-133; 1987: 32-33); etc. See Alai 1994, ch. 3.
} 
rotates around it, or that the Sun is motionless and the Earth rotates around it, or that both move in space, etc. (Goodman 1978, ch.VII).

But the impossibility of choosing in such cases is not a problem, because equivalent descriptions are simply descriptions of the same systems couched in different conceptual schemes, or in different coordinate systems, or frames of reference: they just express the same content in a different form, that is why they are mutually compatible (Alai 1994, ch. 3). ${ }^{9}$

\section{Transient but recurrent underdetermination}

Kyle Stanford $(2001,2006)$ agrees with realists that no successful argument has been presented for the general underdetermination of theories by all the possible empirical evidence (nor, a fortiori, for their underdetermination by empirical evidence and theoretical considerations). However, he describes a form of provisional underdetermination (i.e., underdetermination by currently available evidence) which we face all the time, and is equally or more threatening for realists. In fact, at any time $t$ there are possible alternatives to the currently accepted theories which we cannot even imagine: because of the limits of our mental capacities and current epistemic conditions, numberless possible alternatives "exceed our grasp". Besides, many of these unimagined alternatives are empirically equivalent to the actually entertained theories, and some of them are also on a par with them from the point of view of theoretical virtues. Therefore underdetermination is a constant phenomenon: even when we actually entertain just one theory, it is empirically and theoretically underdetermined with respect to its virtual alternatives.

It might seem that this underdetermination is not an unsolvable problem and a dramatic predicament, since it is "transient" in new evidence, by which many of the theories which are empirically and theoretically equivalent at time $t$ will be ruled out at a later moment $t$ '. But the trouble with this transient underdetermination is its recurring character: no matter how much new evidence comes in and how many actual or virtual competitors are ruled out at the later time $t^{\prime}$, so many others will remain compatible with all the empirical and theoretical constraints at $t^{\prime}$, and so on for any later time. This is a direct consequence of the logical point that there is an infinite number of possible theories compatible with any given body of data.

One might think that Stanford's transient underdetermination is not very different from the epistemological platitude that we cannot ever be certain of the truth of our theories, because we don't know all the relevant data. Yet, whenever only one theory $\mathbf{T}$ is actually accepted, our awareness that we don't know all the relevant data results in the lack of certainty that $\mathbf{T}$ is true; but if we think of $\mathbf{T}$ as

\footnotetext{
9 Davidson attacked the scheme-content distinction, but I have argued that his criticism fails, or at any rate it cannot prevent this solution to the problem of equivalent descriptions (Alai 1994, ch. 4).

10 As it is called by Sklar $(1975,1981)$.
} 
just one among a host of unconceived and possibly better alternatives, as Stanford suggests, the same awareness results in the practical certainty that $\mathbf{T}$ is false.

Stanford's historic examples make his case very convincing: when Aristotelian mechanics was accepted, it was extremely well supported by empirical evidence and theoretical considerations; but it was also just impossible to conceive something like Cartesian mechanics, which centuries later became much better supported and superseded it. Yet, in Descartes' time it was impossible even to imagine Newtonian mechanics, and then relativistic mechanics, each of which in turn gained better support than its predecessor (Stanford 2009a). Moreover, there are similar and well known examples in electromagnetism, chemistry, cytology, etc. (Stanford 2009b, 263-265). Therefore, not only underdetermined alternatives are always there, but apparently the true one is always among those overlooked by the scientists. That is to say, the historical record is that all theories that were actually adopted were false. Now, this is not very different from the other main antirealistic argument, the infamous pessimistic historical meta-induction, which Stanford's examples immediately recall: just as all past theories turned out to be false, so also current ones are probably false, and future ones will be false as well.

Therefore, Stanford's argument differs from the simple caution that we cannot ever be certain that our theories are true precisely to the extent that it replicates the pessimistic meta-induction. As such, however, it can be resisted by the same two strategies followed by realists against the pessimistic induction (see Alai 2017, § 1):

(1) Noticing that science progresses in a number of very concrete and measurable ways: available data increase, instruments and methodologies are improved, the quantity of researchers, publications and resources grows all the time. Moreover, this progress has become faster and faster in the last decades (Fahrbach 2011; Cordero, 2017a, 2017b). It can hardly be disputed that all this allows us to conceive better and better theories and to rule out more and more theories which do not satisfy some empirical or theoretical constraints. Therefore, the number of unconceived but epistemically reasonable theories today is certainly smaller than in the past, and it will be even smaller in the future. Hence the probability that our theories are radically wrong diminishes all the time. They might still be false, and we don't have an absolute measure of that probability, but one cannot simply and straightforwardly infer from the failures of the past to analogous failures of today or tomorrow.

(2) In addition, Stanford's pessimism (like the pessimistic induction) can be resisted by Kitcher's (1993) and Psillos' (1999) deployment realist strategy: many of the best theories at each time, although later recognized as false, included some true claims, which are preserved in successor theories. This must be the case, otherwise the novel predictions issued by those theories would be a miracle (Alai 2014b).

Authors largely agree on a few criteria for identifying the true components of false theories: playing an essential role the theory's success (Psillos 1999: 
109-111; Votsis 2011; Peters 2014; Cordero 2017a, b a); resisting hostile probing (Peters 2014; Cordero2017a, b); describing objects and/or properties which have causal interactions with us and/or the observed phenomena (Chakravartty 1998; 2007: 47; Ghins 2017), and are measurable by independent methods (Kosso 1992: ch. 9; Ghins 2017). In particular, I argued that we can identify claims that are at least partially true, and this of course is compatible with subsequently discovering that such claims also include some false content, so they are false tout court and call for replacement by more completely true claims (Alai $2021 \S 5$ ).

Therefore Stanford's underdetermination (just like the pessimistic induction) does not show that we are unable to achieve theoretical truth; it simply shows that (a) we haven't reached the whole truth, yet; (b) possibly we won't ever reach it (perhaps we would reach it only at the ideal limit of inquiry, if we could get there); (c) we don't know "how far" we are from it now (assuming talk of distance makes sense here); and (d) quite possibly there will still be radical scientific changes in future science.

\section{Conclusion}

In (Alai 2019) I had argued that, although in principle it seems undeniable that theories are underdetermined by data, this has never been a practical problem in the history of science. This is because theories are not underdetermined by theoretical virtues. Moreover, such virtues are not only pragmatically relevant, but offer good reasons to believe in the truth of particular components of theories. However, realism has been challenged also by citing classes of theories which are purportedly underdetermined even by theoretical virtues. In this paper I argued that these challenges can be met, because the truth of theories produced by trivial permutations, or of "equivalent descriptions" is compatible with the truth of standard theories, while "as if" versions of standard theories are much worse from the point of view of theoretical virtues. As for mathematically intertranslatable theories, it may happen that future developments make them empirically decidable, or that theoretical virtues allow choose between their different ontologies. If not, it is not a problem for realists granting that certain issues may de facto escape our knowledge now or forever. Besides, I argued that Stanford's underdetermination with respect unconceived alternatives differs from the simple caution that we cannot ever be certain that our theories are true only by replicating the pessimistic meta-induction from the falsity of all past theories. Therefore, it can be resisted by the two main strategies used by realists against the latter argument: (a) considering the radical advancement of present with respect to past science, and (b) arguing with selective realism that successful theories, even if false, always included some true components. 
Funding Open access funding provided by Università degli Studi di Urbino Carlo Bo within the CRUICARE Agreement. Research supported by the University of Urbino (Contributo d'ateneo PRIN 2015 and DiSPeA research projects 2017-2018-2019) and by the MIUR (PRIN 2017 "The Manifest Image and the Scientifici Image").

Open Access This article is licensed under a Creative Commons Attribution 4.0 International License, which permits use, sharing, adaptation, distribution and reproduction in any medium or format, as long as you give appropriate credit to the original author(s) and the source, provide a link to the Creative Commons licence, and indicate if changes were made. The images or other third party material in this article are included in the article's Creative Commons licence, unless indicated otherwise in a credit line to the material. If material is not included in the article's Creative Commons licence and your intended use is not permitted by statutory regulation or exceeds the permitted use, you will need to obtain permission directly from the copyright holder. To view a copy of this licence, visit http://creativecommons.org/licen ses/by/4.0/.

\section{References}

Acuña P, Dieks D (2014) Another look at empirical equivalence and underdetermination of theory choice. Eur J Philos Sci 4(2):153-180

Alai M (1994) Modi di conoscere il mondo. Soggettività, convenzioni e sostenibilità del realismo. Franco Angeli, Milano

Alai M (2008) $\Sigma \omega ́ \zeta \varepsilon ı \nu \alpha \dot{\alpha} \varphi \alpha \imath \nu \dot{\mu} \varepsilon \nu \alpha$. Realistic and Antirealistic Attitudes in Natural Science. Isonomia. http://isonomia.uniurb.it/vecchiaserie/2008alai.pdf

Alai M (2014a) Why antirealists can't explain success”. In: Bacchini F, Caputo S, Dell'Utri M (eds) Metaphysics and ontology without myths. Cambridge scholars publishing, Newcastle upon Tyne 2014, pp. 48-66

Alai M (2014b) Novel predictions and the no miracle argument. Erkenntnis 79(2):297-326

Alai M (2017) Resisting the historical objections to realism: is Doppelt's a viable solution? Synthese 194(9):3267-3290

Alai M (2019) The underdetermination of theories and scientific realism. Axiomathes 29(6):621-637

Alai M (2021) The Historical Challenge to Realism and Essential Deployment. In: Lyons T, Vickers $\mathrm{P}$ (eds) Contemporary scientific realism: the challenge from the history of science (forthcoming) Oxford University Press, Oxford

Bangu S (2006) Underdetermination and the argument from indirect confirmation. Ratio 19:269-277

Chakravartty A (1998) Semirealism. Stud Hist Philos Sci Part A 29(3):391-408

Chakravartty A (2007) A metaphysics for scientific realism: knowing the unobservable. University Press, Cambridge

Cordero A (2001) Realism and underdetermination: some clues from the practices-up. Philos Sci 68:301-312

Cordero A (2017a) Retention, truth-content and selective realism. In: Agazzi E (ed) Varieties of Scientific Realism. Springer, Cham, pp 245-256

Cordero, A. 2017b "Making content selective realism the best realist game in town", Quo Vadis Selective Scientific Realism? Conference, Durham, UK 5 - 7 August 2017.

Dieks D (2017) underdetermination realism and objectivity in quantum mechanics. In: Agazzi E (ed) Varieties of Scientific Realism. Springer, Objectivity and Truth in Science. Cham etc., pp 295-314

Earman J (1993) Underdetermination, Realism, and Reason. Midwest Stud Philos 18:19-38

Fahrbach L (2011) Theory change and degrees of success. Philos Sci 78:1283-1292

Fano V (2005) Comprendere la scienza. Un'introduzione all'epistemologia delle scienze naturali, Liguori, Napoli

French S (2011) Metaphysical underdetermination: Why Worry? Synthese 180(2):205-221

French S, Ladyman J (2011) In defence of ontic structural realism. In: Structuralism S (ed) Alisa Bokulich and Peter Bokulich. Springer, Dordrecht, pp 25-42

Friedman M (1983) Foundations of space-time theories. University of Chicago Press, Chicago

Ghins M (2017) Selective Scientific Realism: Representation, Objectivity and Truth. In: Agazzi E (ed) Varieties of scientific realism. Springer, Cham, pp 109-131 
Glymour C (1970) Theoretical equivalence and theoretical realism. Proc Bienn Meet Philos Sci Ass 1970:275-288

Glymour C (1977) The Epistemology of Geometry. Noûs 11:227-251

Glymour C (1980) Theory and evidence. Princeton University Press, Princeton, NJ

Glymour C (2013) Theoretical equivalence and the semantic view of theories. Philos Sci 80:286-297

Goodman N (1978) Ways of worldmaking. Hackett, Indianapolis-Cambridge

Halvorson H (2012) What scientific theories could not be. Philos Sci 79:183-206

Halvorson H (2013) The semantic view, if plausible, is syntactic. Philos Sci 80:475-478

Kitcher P (1993) The advancement of science. Oxford University Press

Kosso P (1992) Reading the book of nature: an introduction to the philosophy of science. Cambridge University Press, Cambridge Mass

Kukla A (1993) Laudan, leplin, empirical equivalence and underdetermination. Analysis 53(1):1-7

Ladyman J, Ross D, Spurrett D, Collier J (2007) Every thing must go: metaphysics naturalised. University Press, Oxford

Laudan L, Leplin J (1991) Empirical equivalence and underdetermination. J Philos 88:449-472

Laudan L, Leplin J (1993) Determination underdeterred: reply to kukla. Analysis 53:8-16

Lyre H (2011) Is structural underdetermination possible? Synthese 180(2):235-247

Musgrave A (2006-2007) The 'miracle argument' for scientific realism. The rutherford journal. the New Zealand journal for the history and philosophy of science and technology Vol 2. http://www.ruthe rfordjournal.org/article020108.html.

Norton J (2008) Must evidence underdetermine theory? In: Carrier M, Howard D, Kourany J (eds) The challenge of the social and the pressure of practice: science and values revisited. University of Pittsburgh Press, Pittsburgh, pp 17-44

Peters D (2014) What Elements of Successful Scientific Theories are the Correct Targets for "selective" scientific realism? Philosophy of Science 81:377-397

Poincaré, Henry. 1902. La science et l'hypothèse. Paris: Flammarion. Engl. transl. Science and Hypothesis. New York: Dover Publications 1952.

Psillos S (1999) Scientific realism how science tracks truth. Routledge, London

Putnam H (1978) Meaning and the moral sciences. Routledge and Kegan Paul, London

Putnam, H. 1978b "Equivalenza", Enciclopedia Einaudi, Einaudi, Torino, vol. V, pp. 547-564. Engl. transl."Equivalence", in H. Putnam, Realism and Reason, Cambridge, Cambridge U.P. 1983, pp. 26-45.

Putnam H (1981) Reason truth and history. Cambridge University Press, Cambridge

Putnam H (1983) Realism and reason, philosophical papers, vol 3. Cambridge U.P, Cambridge

Putnam H (1987) The many faces of realism. Open Court, LaSalle, Illinois

Quine WVO (1958) Speaking of objects. Proc Addresses Am Philos Ass 31:5-22

Sklar L (1975) Methodological conservatism. Philos Rev 84:384-400

Sklar L (1981) Do unborn hypotheses have rights? Pac Philos Q 62:17-29

Sklar L (1982) Saving the noumena. Philos Top 13:49-72

Stanford PK (2001) Refusing the devil's bargain: What kind of underdetermination should we take seriously? Philos Sci [Proc] 68:S1-S12

Stanford PK (2006) Exceeding our grasp: science, history, and the problem of unconceived alternatives. Oxford University Press, Oxford

Stanford PK (2009) Scientific realism, the atomic theory, and the catch-all hypothesis: Can we test fundamental theories against all serious alternatives? Br J Philos Sci 60(2):253-269

Stanford, P.K. 2009a,Underdetermination of scientific theory, Stanford Encyclopedia of Philosophy https://plato.stanford.edu/entries/scientific-underdetermination/

Van Fraassen B (1980) The scientific image. Oxford University Press, Oxford

Votsis I (2011) The prospective stance in realism. Philos Sci 78:1223-1234

Worrall J (1989) Structural realism: The best of both worlds? Dialectica 43:99-124

Publisher's Note Springer Nature remains neutral with regard to jurisdictional claims in published maps and institutional affiliations. 